\title{
Impact of Different Transgenic and Conventional Cotton Cultivars on Population Dynamics of Whitefly, Bemisia Tabaci
}

\author{
Bilal Atta $^{1, *}$, Fatima Mustafa ${ }^{1}$, Muhammad Adil ${ }^{3}$, Muhammad Fahad Raza ${ }^{2}$, Muhammad Asif Farooq ${ }^{1}$ \\ ${ }^{1}$ Department of Entomology, University of Agriculture, Pakistan \\ ${ }^{2}$ Department of Entomology, Pir Mehr Ali Arid Agriculture University, Pakistan \\ ${ }^{3}$ Institute of Horticultural Sciences, University of Agriculture, Pakistan
}

Copyright $(\odot 2015$ by authors, all rights reserved. Authors agree that this article remains permanently open access under the terms of the Creative Commons Attribution License 4.0 International License

\begin{abstract}
The current study was conducted to assess the performance of transgenic and conventional cotton cultivars in response to population dynamics of whitefly (Bemisia tabaci) in field under RCBD. Five transgenic cotton cultivars (FH-4243, FH-167, FH-113, FH-187 and FH-114) and five conventional cotton cultivars (FH-942, FH-1000, FH-207, FH-901 and FH-941) were used during this study. On the numerical basis, results revealed that transgenic cotton cultivars were more susceptible to whitefly infestation as compared to conventional cotton cultivars. The pooled comparison of whitefly/leaf on different tested cotton cultivars revealed highly significant variations. The results showed that maximum population of whitefly was observed on FH-113 (3.12 whitefly/leaf) while minimum whitefly population was observed on FH-941 (1.89 whitefly/leaf). When data was statistically analyzed, whitefly population on transgenic and conventional cotton cultivars revealed that transgenic cotton cultivars had higher level of whitefly $(2.68$ whitfly/leaf) compared to conventional cotton cultivars $(2.36$ whitefly/leaf).
\end{abstract}

Keywords Population Dynamics, Bemisia Tabaci, Transgenic And Conventional Cotton Cultivars

\section{Introduction}

The king of natural fiber is Cotton (Gossypium Spp.) which is grown in 111 countries throughout the world [1]. It is not only major cash crop but also each and every parts of the cotton plant are useful to farmer in one way or the other [2]. The major reason of reduction in cotton yield and quality is the attack of about 150 different species of insect and mite pests [3]. Cotton is susceptible to be attacked from a large number of pest insects, throughout its growth period. Whitefly, Bemisia tabaci; aphids, Aphis gossypii; leafhopper, Amrasca biguttula biguttula; leaf beetle, Cerotoma trifurcate; red cotton bug, Dyesdercus koenigii are the major sucking insect pests recorded on cotton. The insects can damage cotton to the tune of $39.50 \%[4,5]$.

Bemisia tabaci has become one of the most important sucking pest of world's industrial and food crops like cotton, sunflower, melon, tomato, brinjal etc. [6,7]. Heavy infestation may reduce plant vigor and growth, cause chlorosis and uneven ripening of bolls. Its direct feeding induces physiological disorders resulting in shedding of immature fruiting parts. Its nymphs produce honeydew, on which black sooty mold grows, reducing the photosynthetic capabilities of plants. This situation results in stunting of plants and lint contamination. It acts as a sole vector of more than 100 plant viruses, which cause diseases to many commercial crops in different parts of the world [8]. It also transmits cotton leaf curl virus disease, a real threat to cotton production in Pakistan.

Key pests of cotton are controlled by broad-spectrum insecticides used in large quantity which cause not only health problems and environmental pollution but also the main reason of development of insecticide resistance against insects [9].

Use of broad-spectrum insecticides has been reduced to great extent with the invention of transgenic cotton. As a result, non-target sucking insect pests of cotton which includes whitefly, thrips, aphids, leaf bugs and spider mites survive better [10] and feed on their host more comfortably. So, there is a dire need to sort out or screen out new cotton lines/varieties relatively resistant to sucking insect pests and mites to fulfill the fiber demands of the population increasing at an alarming rate of $2.9 \%$.

The present study was conducted to compare transgenic and conventional cotton cultivars for whitefly incidence, study the population dynamics and seasonal abundance of whitefly on cotton to identify the peak abundance period.

\section{Materials and Methods}

The present study was carried out to investigate the performance of five transgenic cotton (FH-4243, FH-167, 
FH-113, FH-187 and FH-114) and five conventional cotton cultivars (FH-942, FH-1000, FH-207, FH-901 and FH-941) in response to population dynamics of whitefly (Bemisia tabaci) at Research area of University of Agriculture, Faisalabad, Pakistan during 2013. The experiment was laid out under Randomized Complete Block Design (RCBD) having three replications. The plot size was $30 \times 70$ feet for each treatment. All possible agronomic practices were carried out to minimize the impact of weeds and alternate hosts of the pests. No plant protection measures, including pesticide application were applied.

The population of whitefly was recorded from the month of 2-May-2013 to 18-September-2013. Sampling was done according to Mario method of pest scouting. Ten plants were selected randomly, from each replication. Whitefly population was recorded from, upper leaf (first plant), middle leaf (second plant), lower leaf (third plant) and so on. The data were recorded fortnightly, for six weeks, continuously.

The data of population dynamics of whitefly was analyzed by one way analysis of variance using the software MSTAT C, and means were separated by Duncan Multiple Range Test (DMRT).

\section{Results}

Population of whitefly on different transgenic and conventional cotton cultivars was recorded from 2-May-2013 to 18-September-2013. Maximum population of whitefly was observed on transgenic cultivars throughout the entire season of 2013, while conventional cultivars showed minimum population of whitefly. Maximum and minimum population of whitefly was observed on FH-113 and FH-941, respectively which gradually increased and decreased throughout the entire season. Population of whitefly on FH-113 was started from 3.94 whitefly/leaf which lasted at 2.01 whitefly/leaf. While population on FH-941 was started from 3.02 whitefly/leaf which lasted at 0.54 whitefly/leaf. FH-113 and FH-941 showed maximum population (6.14 and 5.52 whitefly/leaf, respectively) at 12-June-2013, while minimum population (1.1 and 0.16 whitefly/leaf, respectively) at 28-August-2013.

Pooled comparison of transgenic verses conventional cotton cultivars in relation to population dynamics of whitefly showed that transgenic cultivars had higher level of whitefly population (5.94 whitefly/leaf) compared to conventional cotton cultivars (5.74 whitefly/leaf) at 12-June-2013, while lower level of whitefly population (0.69 whitefly/leaf) as compared to conventional cotton cultivars (0.59 whitefly/leaf) at 28-August-2013 (Figure 1). Maximum whitefly population (5.84 whitefly/leaf) was observed at 12-June-2013 after combination of both transgenic and conventional cotton cultivars.

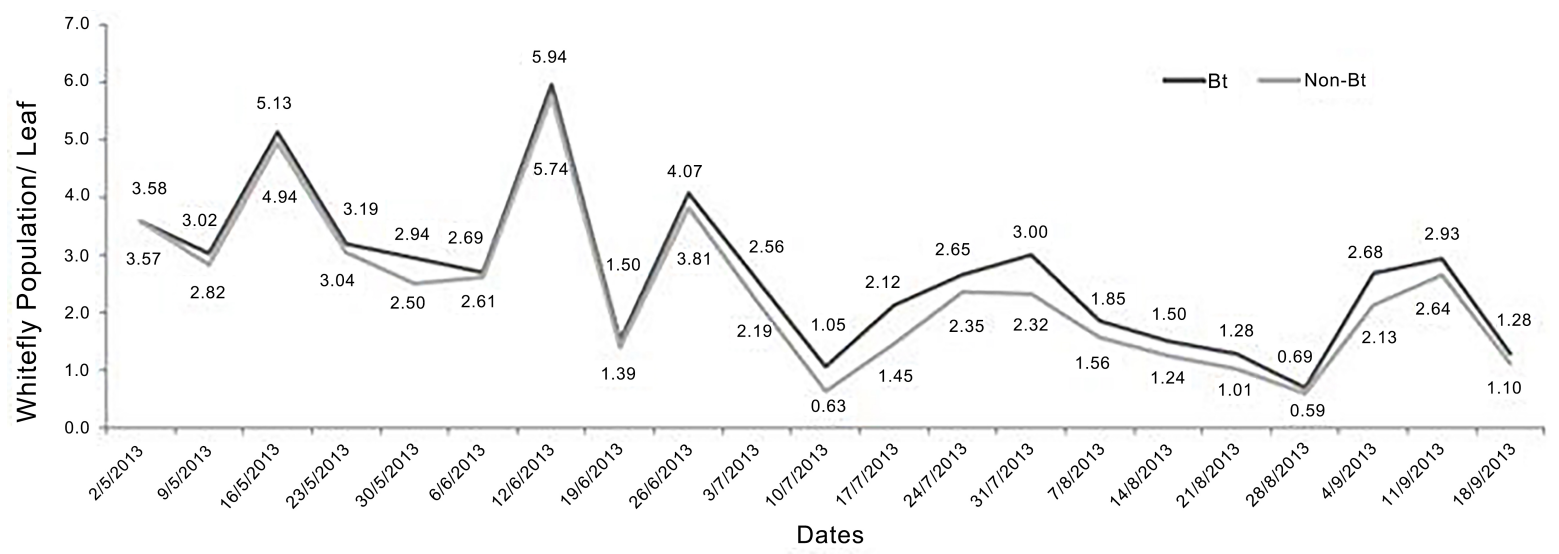

Figure 1. Population dynamics of Whitefly on transgenic and conventional cotton cultivars during entire season of 2013.

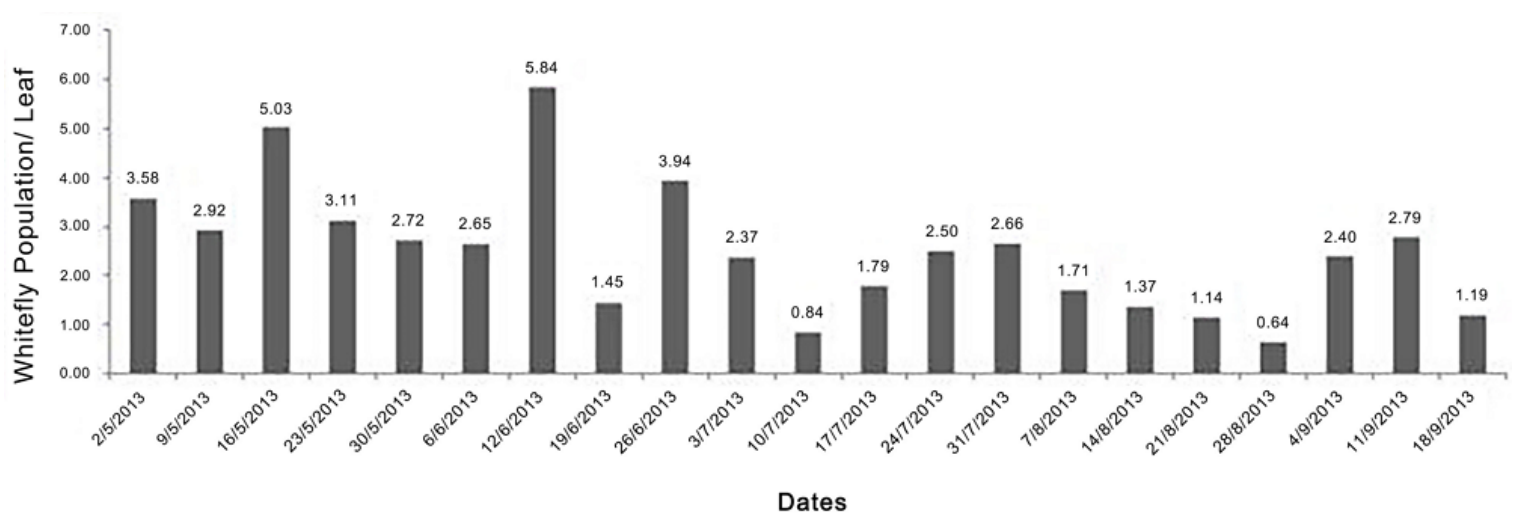

Figure 2. Population dynamics of Whitefly on transgenic and conventional cotton cultivars during entire season of 2013. 


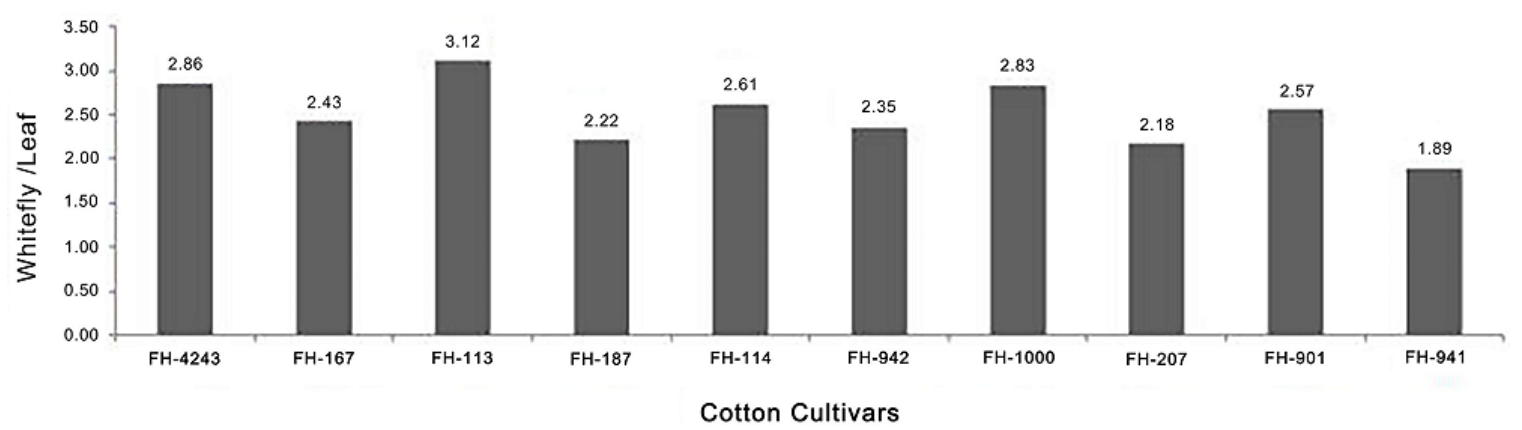

Figure 3. Mean population of Whitefly on transgenic and conventional cotton cultivars during entire season of 2013.

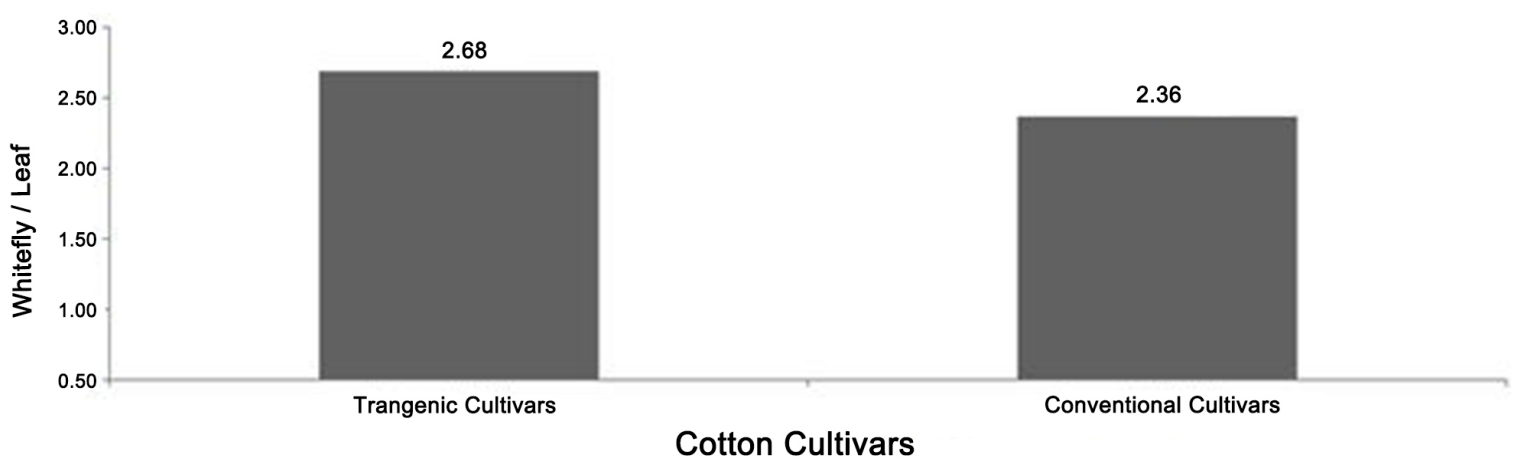

Figure 4. Mean population (Pooled) of Whitefly on transgenic and conventional cotton cultivars during entire season of 2013.

\subsection{Mean comparison of Bemisia tabaci population on transgenic and conventional cotton cultivars during entire season of 2013}

The results revealed that the highest mean population of $B$. tabaci was observed on transgenic cotton cultivar, FH-113, (3.12 whiteflies/leaf) while minimum mean population was recorded on conventional cotton cultivar, FH-941 (1.89 whiteflies/leaf) during entire season of 2013 (Figure 3).

\subsection{Mean comparison (Pooled) of Bemisia tabaci population on transgenic and conventional cotton cultivars during entire season of 2013}

The pooled analysis of $B$. tabaci population on transgenic and conventional cotton cultivars revealed that transgenic cultivars had higher population level (2.68 whiteflies/leaf) while conventional cultivars had lowest population level (2.36 whiteflies/leaf) during entire season of 2013 (Figure 4).

\section{Discussion}

The results revealed that maximum populations of $B$. tabaci was recorded o transgenic cotton cultivars (FH-4243, FH-167, FH-113, FH-187 and FH-114) while minimum populations were recorded on conventional cotton cultivars (FH-942, FH-1000, FH-207, FH-901 and FH-941). Maximum mean population of whitefly was observed on FH-113, while minimum whitefly population was observed on FH-941.

However, previously reported studies by Jeyakumar et al. [11] had shown higher incidence of whitefly in Bt cotton hybrids. This was, however, probably due to limited or no feeding by bollworms and not because of higher whitefly susceptibility [12]. Akram et al. [13] found during study that $B t$ genotypes were more susceptible host for the whitefly and thirps than non- $B t$ genotypes.

Dhillon and Sharma [14] conducted an experiment to check the effect of $B t$-transgenic and non-transgenic cotton on arthropod diversity. The results indicated that whitefly, Bemisia tabaci was higher on Bt-transgenic than on non-transgenic cotton.

Abundance of cotton whitefly was greater on $B t$-transgenic than on non-transgenic cotton. This may be because of the glabrous nature of the hybrid tested in the present studies, which is more susceptible to sucking pests [15].

Khan et al. [16] evaluated genetically engineered cotton genotypes, Gossypium hirsutum L., (Bt-121, Bt-196, Bt-313, Bt-333, Bt-496, Bt- 703, Bt-802, Bt-1524, Bt-3701, Bt-W1) evaluated for their resistance against whitefly, Bemisia tabaci (Genn.), during the cropping seasons 2008 and 2009. In 2008, Bt-496 showed highest susceptibility to $B$. tabaci (4.52 population/leaf) followed by $B t-121(3.55$ population/leaf) and $B t-3701$ (3.19 population/leaf) while all the remaining varieties were statistically at par having minimum population per leaf ranging from 1.97 to 2.75 . In 2009, Bt-496 showed highest susceptibility to B. tabaci (4.97 population/leaf) followed by $B t-333$ (4.25 population/leaf) while all the remaining varieties were statistically at par having population ranging from 2.09 to 3.59 per leaf except $B t-703$ which showed highest resistance to $B$. tabaci (1.41/leaf). 


\section{Conclusions}

In the light of above mentioned results and numerical data, it is concluded that transgenic cotton cultivars were more susceptible to whitefly infestation as compared to conventional cotton cultivars. Maximum population of whitefly was observed on FH-113 while minimum whitefly population was observed on FH-941. Need of the time is to screen out new cotton lines/varieties which are relatively resistant to sucking insect pests.

\section{REFERENCES}

[1] Anonymous, Training manual on DVS test in cotton with resistance to PPV and FR legislation 2001, All India Coordinated Cotton Improvement Project CICR Coimbatore Tamil Nadu, pp.134-135, 2005.

[2] B. K. Shivanna, D. N. Nagaraja, M. Manjunatha, M. I. Naik, Seasonal incidence of sucking pests on transgenic $B t$ cotton and correlation with weather factors, Karnataka Journal of Agricultural Sciences, Vol. 22, 666-667, 2009.

[3] M. R. Attique, A. Rashid, Efficacy of pyrethroid pesticides for the control of cotton pests, Journal of Agricultural Research, Vol. 4, 65-67, 1983.

[4] K. M. Naqvi, Crop Protection to boost up cotton production, Paper read at cotton seminar, on April 13-14, 1975 at Layllpur, 1975.

[5] G. Q. Chaudhry, Pest control in cotton production, Proc. Cotton production seminar organized by Esso fertilizer company Ltd., Pakistan,, pp.114-118, 1976.

[6] Anonymous, Bemisia tabaci (Gennadius), Distribution Maps of Pests' Series A No. 284 (Revised), Commonwealth Institute of Entomology, London, 1986.

[7] A. H. Greathead, Host plants. In: Cock, (ed.), Bemisia tabaci, A Literature Survey on the Cotton Whitefly with an Annotated Bibliography, CAB International UK, pp. 17-26. 1986.
[8] D. R. Jones, Plant viruses transmitted by whiteflies, European Journal of Plant Pathology, Vol. 109, 195-219, 2003.

[9] A. I. Mohyuddin, G. Jillani, A. G. Khan, A. Hamza, I. Ahmad, Z. Mahmood, Integrated pest management of major cotton pests by conservation, redistribution and augmentation of natural enemies, Pakistan Journal of Zoology, Vol. 29, 293-298, 1997.

[10] W. H. Xu, B. Liu, R. M. Wang, Y. P. Zheng, Y. Zhang, X. G. $\mathrm{Li}$, Effects of transgenic $B t$ cotton on insect community in cotton fields of coastal agricultural area of Jiangsu province, Journal of Ecology and Rural Environment, Vol. 24, 32-38, 2008 .

[11] P. Jeyakumar, R. K. Tanwar, M. Chand, A. Singh, D. Monga, O. M. Bambawale, Performance of $B t$ cotton against sucking pests, Journal of Biopesticides, Vol. 1, 223-225, 2008.

[12] F. D. Wilson, H. M. Flint, W. R. Deaton, D. A. Fischhoff, F. J. Perlak, T. A. Armstrong, R. L. Fuchs, S. A. Berberich, N. J. Parks, B. R. Stapp, Resistance of cotton lines containing a Bacillus thuringiensis toxin to pink bollworm (Lepidoptera: Gelechiidae), Journal of Economic Entomology, Vol. 85, 1516-1521, 1992.

[13] M. Akram, F. Hafeez, M. Farooq, M. Arshad, M. Hussain, S. Ahmed, K. Zia, H. A. A. Khan, A case to study population dynamics of Bemisia tabaci and Thrips tabaci on Bt and non- $B t$ cotton genotypes, Pakistan Journal of Agricultural Sciences, Vol. 50, No. 4, 617-623, 2013.

[14] M. K. Dhillon and H. C. Sharma, Comparative studies on the effects of $B t$-transgenic and non-transgenic cotton on arthropod diversity, seedcotton yield and bollworms control, Journal of Environmental Biology, Vol. 34, 67-73, 2013.

[15] H. C. Sharma and R. A. Agarwal, Role of some chemical components and leaf hairs in varietal resistance in cotton to jassid, Amrasca biguttula biguttula Ishida. Journal of the Entomological Research Society, Vol. 7, 145-149, 1983.

[16] M. A. Khan, W. Akram, H. A. A. Khan, J. Asghar and T. M. Khan, Impact of Bt-cotton on Whitefly, Bemisia tabaci (Genn.) population, Pakistan Journal of Agricultural Sciences, Vol. 47, No. 4, 327-332, 2010. 